\title{
Shared intention and the doxastic single end condition
}

Blomberg, Olle

Published in:

Philosophical Studies

DOI:

10.1007/s11098-015-0496-z

Publication date:

2016

Document version

Peer reviewed version

Citation for published version (APA):

Blomberg, O. (2016). Shared intention and the doxastic single end condition. Philosophical Studies, 173(2), 351372. https://doi.org/10.1007/s11098-015-0496-z 


\title{
Shared intention and the doxastic single end condition
}

\begin{abstract}
What is required for several agents to intentionally $\varphi$ together? I argue that each of them must believe or assume that their $\varphi$-ing is a single end that each intends to contribute to. Various analogies between intentional singular action and intentional joint action show that this doxastic single end condition captures a feature at the very heart of the phenomenon of intentional joint action. For instance, just as several simple actions are only unified into a complex intentional singular activity if the agent believes or assumes that there is a single end that each action is directed to, so several agents' actions are only unified into an intentional joint activity if each agent believes or assumes that there is a single end that each intends to contribute to. Influential accounts of intentional joint action, including Christopher Kutz's and Michael Bratman's, implicitly include this condition only if participants must intend to contribute to the end under the same conception. While such a requirement successfully rules out some counterexamples, it also makes the accounts unable to appropriately accommodate and explain clear cases of intentional joint action that they ought to be able to accommodate and explain.
\end{abstract}

Keywords: intentional joint action, shared intention, common goal, doxastic single end condition, Christopher Kutz, Michael Bratman

Word count: 12,000 words including references and footnotes. 


\section{Introduction}

Suppose that you are out hunting in the forest. You intend to catch the animal that casts a shadow on the forest floor. Suddenly the sun is blocked by a dark cloud and the shadow disappears. But you notice the rustling of leaves in the canopy of the trees and you continue the hunt, now intending to catch the animal that rustles the leaves. Are the hunting actions you perform before and after the sun is blocked out parts of the same intentional activity of pursuing the animal (the one that first casts the shadow and then rustles the leaves)? This depends on whether you believe that the animal being caught is a single end that all your actions, those performed before and after the sun is blocked out, are directed to. It isn't sufficient that your actions are in fact directed to a single end. If you believe that the animal that casts the shadow and the animal that rustles the leaves are distinct, then your actions will not be intentionally jointly directed at catching the animal. On the other hand, if you do believe that there is a single end that all your actions are directed to, then the actions are intentionally jointly directed at catching the animal even if you represent the end differently before and after the sun is blocked out.

An intentional action can be performed by several agents together as well as by a single agent. I can intentionally catch the animal on my own or we can intentionally catch it together. Does the principle of composition that I just appealed to in the singular case also apply in the joint case? I will argue that it does. ${ }^{1}$ For

\footnotetext{
${ }^{1}$ I take it to be intuitively plausible that this principle holds in the singular case. As far as I know, it is not explicitly part of any existing theory of intentional singular activity (see e.g. Dalton, 1995). While the arguments I present here are concerned with intentional joint action, they arguably also lend support to the claim that the principle or condition should be part of a theory of intentional singular activity. As Chant (2006, p. 439) suggests, theories of joint action may shed light on the undertheorised phenomenon of intentional singular activity.
} 
several agents' actions to constitute an intentional joint action, each agent must, roughly, believe or assume that there is a single end that each intends to contribute to. This single end may be a conjunctive end, so the condition does not exclude that there is a (single) plurality of ends that each intends to contribute to. Rather, the condition should be understood as follows: Each agent must believe or assume that each intends to contribute to the end that they themselves intend to contribute to. If they do not believe or assume this, then they do not have a "shared intention" to bring about the end, where 'shared intention' is the placeholder for whatever it is that turns a joint action into an intentional joint action. By 'end' I here simply mean a state of affairs or activity that one or more agents intends to bring about or contribute to.

Perhaps you think that this doxastic single end condition (as I call it) is already embedded in most accounts of shared intention or intentional joint action. ${ }^{2}$ However, I will show that this is only true if it is assumed that the agents intend to bring about the end under the same conception (Bratman (2014, p. 42) explicitly assumes this; Miller (1995, p. 53) explicitly requires it). Furthermore, it must also be assumed that the agents accurately ascribe intentions that represent the end

\footnotetext{
${ }^{2}$ Versions of the condition are implicit in Ludwig (2007), Gilbert (2009) and Butterfill (forthcoming). As far as I am aware, the condition is explicitly included in only two accounts, namely Searle's (2010, p. 53) and Blomberg's (forthcoming). According to Searle (2010, p. 53), "[i]n order to engage in collective behavior I have to believe (or assume or presuppose) that others are cooperating with me. And their cooperation will consist in their having intentions-in-action that specify the same goal [end] as I have but need not specify the same means to the goal."

I have avoided formulating the condition in terms of agents believing that each intends to contribute to "the same" goal or end because this may suggest that participants must first think of several ends and then judge that the ends are identical. But each participant may simply think of the end she intends to contribute to as an end that others also intend to contribute to, without making any judgement of identity. Furthermore, such a formulation may suggest that the notion of "the same end" must figure in the content of the participants' intentions. But the requirement is not that each believes that each intends to contribute to the same end as that which the others intend to contribute to, irrespectively of which end this is.
} 
under this same conception to each other. ${ }^{3}$

Unfortunately, with this same-conception assumption, the accounts fail to accommodate and explain clear cases of intentional joint action that the account arguably ought to be able to accommodate and explain. Just as all my actions can be parts of the intentional singular activity of catching the animal even if I don't conceive of the end in the same way before and after the sun is blocked out, so my and your actions can be parts of an intentional joint activity of catching the animal even if we don't intend that we bring about the end under the same conception. Indeed, Bratman acknowledges this possibility when he suggests that "[p]erhaps we can share an intention to go to NYC [New York City] if I intend that we go to the city that is the home of the Yankees and you intend that we go to the city that is the home of the Mets" $(2014$, p. 42$){ }^{4}$

However, without the same-conception assumption, accounts such as Bratman's fail to provide collectively sufficient conditions for shared intention and intentional joint action. The accounts then fail to rule out cases where each agent mistakenly believes that there is no single end that each intends to contribute to (where ends are individuated extensionally ${ }^{5}$ ). I am not a party to a shared intention to go to NYC if I (i) intend that we go to the home city of the Yankees, (ii) correctly believe that you intend that we go to the home city of the Mets, and (iii)

\footnotetext{
${ }^{3}$ As Smith (2006, pp. 279, 282) puts it, shared intention seems to presuppose conceptual agreement as well as epistemic agreement.

${ }^{4}$ The Yankees and the Mets are rival baseball teams, both from NYC.

${ }^{5}$ The dilemma remains if one insists on individuating ends with respect to the conceptions under which they are represented. It merely has to be reformulated: The accounts fail to provide sufficient conditions for intentional joint action unless they require that agents intend to contribute to the same end, but if the accounts require this, then they fail to appropriately accommodate and explain many cases of intentional joint action that ought to be accommodated and explained. The solution to the dilemma must then be put in terms of a condition that each participant must believe or assume that there is a single outcome or activity that realises the intended end of each.
} 
falsely believe that the end I intend that we bring about isn't a single end that is intended by each of us. This is a kind of Frege case, where I fail to realise that the conception under which I represent my intended end and the conception under which I represent your intended end are co-referential. ${ }^{6}$ I will later explain how it is possible for rational agents to end up in this kind of Frege case. Arguably, our going to NYC would not be intentionally joint if we went there as a result of these intentions and beliefs of mine and the corresponding intentions and beliefs of yours. If I believe that there are distinct ends that you and I intend to bring about, then I will not care about the realisation of your end in the right way. I may treat your agency as a resource to exploit rather than as an agency that is (or will be) joined with my own agency. As we will see, analogies between singular and joint action also show that this kind of Frege case isn't a case of intentional joint action.

Many accounts need the doxastic single end condition, but I will focus on Kutz's minimalistic account of intentional joint action and Bratman's influential account of a robust form of intentional joint action that he calls "shared intentional activity" (Kutz, 2000a; Bratman, 2014). ${ }^{7}$ I present Kutz's account in section 3 and discuss whether and why a core feature of intentional joint action is that there is a single end that each participant intends to contribute to. I do this by highlighting an interpretive ambiguity in Kutz's account regarding what is required for the

\footnotetext{
${ }^{6}$ If I represent your intended end under the same conception that I represent my own intended end, then I must believe that there is a single end that is intended by each of us. In other words, I am assuming that same conception implies same extension, in the way that same mode of presentation or "aspectual shape" (Searle, 1992, p. 155) implies same extension.

${ }^{7}$ For what it is worth, I believe that at least Tuomela and Miller (1988), Miller (2001), Alonso (2009) and Pacherie (2011) need to incorporate the doxastic single end condition. Blomberg (2015) argues that Butterfill's (2012) account of goal-directed joint action needs to incorporate a condition similar to the doxastic single end condition.
} 
participants' intentions to "overlap". In section 4, I present the dilemma that have I sketched in the last two paragraphs, as it pertains to what I argue is the best construal of Kutz's account. In section 5, I show how Kutz can avoid the dilemma by adopting the doxastic single end condition. I then present Bratman's account in section 6 . In section 7, I show that his account faces the dilemma too. Fortunately, as I explain in section 8, a version of the doxastic single end condition also saves Bratman's account.

But first, it will be useful to put some preliminary constraints and resources for theorising about intentional joint action on the table. This is what I do in the next section.

\section{Preliminary constraints and resources}

According to Davidson (2000, p. 46), "a man is the agent of an act if what he does can be described under an aspect that makes it intentional." Call this Davidson's thesis. Suppose I intentionally put the contents of a tube on my toothbrush and falsely believe that it contains toothpaste rather than moisturising cream. In this case, I do not intentionally put moisturising cream on my toothbrush, but I'm nevertheless the agent of this action since it is intentional under the description "putting the tube's contents on my toothbrush." Contrast this with the case where you push me so that I drop the toothbrush. The dropping of the tooth brush is not an action of mine at all, since it is not intentional under any description.

What does this tell us about joint action? A natural thought is that, by analogy, several agents perform a joint action only if what they do can be described as joint under an aspect that makes the participation of each agent intentional. The joint 
action is only intentionally joint under such a description (Kutz, 2000a, p. 21; Tuomela, 2007, p. 111; Pacherie, 2011, p. 175). Call this the description analogy. Two constraints have been derived from this analogy. First, each agent must intentionally take part in the joint action under a description of it as joint. Thus, each agent must intentionally contribute to the end that they, themselves and the others, do something. If we intentionally go for a walk together, then each must intentionally contribute to the collective end that we walk. Here, it is important to note the danger of a vicious analytical circularity that should be avoided. The participants' own notion of the collective end that they intentionally contribute to cannot be the notion of an intentional joint action (at least not in every case). This would embed the very notion that we are trying to give an analysis of in the analysans itself, making the account uninformative (for discussion, see Petersson, 2007). While Kutz and Bratman insist that participants sometimes intend to contribute to or bring about intentional joint actions, both nevertheless appeal to weaker notions of joint action to characterise what participants must intentionally contribute to (for details, see section 3 and section 6).

Secondly, it may be thought that in order for the joint action to be intentionally joint, the agents must have a common conception of the collective end that each intentionally contributes to. This is because it seems that the agents' joint $\varphi$-ing can be described under an aspect that makes it intentional for each only if each agent conceives of the $\varphi$-ing under that aspect. As Kutz puts it, "[s]o long as the members of a group overlap in the conception of the collective end to which they intentionally contribute, they act collectively, or jointly intentionally.” (2000a, p. 17) For there to be overlap in the conception of the collective end, the participants must, at some level of descriptive granularity, have a common conception 
of it. According to Kutz, the joint action is only jointly intentional under a description that corresponds to some such common conception. While I think this is ultimately mistaken, it certainly seems like a plausible idea in light of Davidson's thesis. Participants may of course also have conceptions of what they are doing that are not shared between them. Kutz puts it as follows:

[A] group act can be jointly intentional under one description and not jointly intentional under another. You may believe we are going to a friend's house for a quiet dinner, while I believe we are going for a surprise party. While our going to the surprise party is not jointly intentional, our going to the friend's house is.

(Kutz, 2000a, p. 21)

Here, our activity is intentionally joint under the description "our going to the friend's house" because each of us participates intentionally in the activity conceived in this way.

These two constraints concern what participants must intentionally contribute to, not what they must intend to contribute to. Philosophers differ on what the relation between intentional action and intention is. According to the so-called Simple View, an agent intentionally $\varphi$-s only if she intends to $\varphi$ (see Adams, 1986). On this view, if you intentionally contribute to our going to the friend's house, then you must intend to contribute to our going to the friend's house. Hence, if the Simple View is accepted, then the description analogy implies that if participants intentionally bring about $E$ jointly, then there must be a single collective end $E$ that each intends to contribute to. But if the Simple View is rejected, then the analogy might allow that there are distinct collective ends that participants intend 
to contribute to. You might intentionally contribute to our going to the friend's house not because you intend to but because you intend to follow me and because you expect that I will take you to the friend's house.

In the next section, I will argue that even if the Simple View is rejected, it is still true that there must be-at least in paradigmatic cases-a single end $E$ that each participant intends to contribute to in order for their bringing about $E$ to be an intentional joint action. ${ }^{8}$ This is due to other considerations that do not have anything to do with Davidson's thesis. Besides the description analogy, two other analogies can provide constraints and resources for theorising about intentional joint action. First, there is the analogy that I opened section 1 with: Just as several simple actions performed by a single agent can be unified into a complex intentional singular activity, so the actions of several agents can be unified into an intentional joint activity (see Chant, 2007, p. 249; Searle, 1990; Laurence, 2011, sect. 3). Call this the unified activity analogy. Furthermore, there is the intention analogy: In the same way that the behaviour of a single agent is her intentional action if it is appropriately caused and coordinated by her intention, so several agents' actions constitute their intentional joint action if it is appropriately caused by the agents' "shared intention". According to this analogy, intentional joint action should involve something that plays a role that is analogous to the role that intention plays in intentional singular action (see Tuomela, 2007, pp. 107-108; Bratman, 2014, pp. 10, 27, 86).

Another source of constraint on accounts of intentional joint action is the idea that it is a form of intentional cooperation (Searle, 1990, p. 406). While some

\footnotetext{
${ }^{8}$ I add "at least in paradigmatic cases" because I want to leave it open whether there may be cases of intentional joint action where the doxastic single end condition is satisfied but where there in fact is no single end that each intends to contribute to. See section 5.
} 
forms of coercion, deception and manipulation might be compatible with intentional joint action (Bratman, 2014, pp. 37-39), each participant must at least treat the others as co-participants or partners rather than as social tools or mere parameters for their own activity (see Kutz, 2000a, p. 7; Pettit and Schweikard, 2006, pp. 22-23; Bratman, 2014, p. 48). In this way, intentional joint action is different from parallel and interdependent intentional action.

Additional considerations may be brought to bear in circumscribing the phenomenon of intentional joint action, but the three analogies I have highlighted and the distinction between joint and merely parallel interdependent action are relatively uncontroversial and widely drawn upon (in contrast to, for example, the idea that intentional joint action necessarily involves certain special normative relations between participants, see Roth, 2004 and Gilbert, 2009). They will all be important in the arguments that follow.

\section{Kutz's account of intentional joint action}

According to Kutz's minimalistic account, a joint action is an intentional joint action if and only if it is the outcome of several agents' "overlapping participatory intentions", where a participatory intention is an ordinary intention to perform an action which frames it as a contribution to a collective end $(2000 a$, p. 4). This collective end rationalises the individual act (2000a, p. 11). The "collectivity" is thus introduced in the content of the intentions, rather than by way of a new type of we-mode attitude or the formation of a plural subject (in contrast to Searle, 1990; Gilbert, 2009).

The notion of collectivity than figures in the participatory intentions can be 
very weak, which enables Kutz to avoid the vicious analytical circularity that might otherwise be introduced into his account. According to Kutz, the notion of a collective end is simply that of an end that is "constituted by or is a causal product of different individuals' acts." (2000a, p. 10). This notion does not imply that the existence of a state of affairs that each is aiming at. Consider the end that an animal is caught as the result of me pursuing the animal and you (intentionally or unintentionally) distracting it. This would be a case that falls under Kutz's notion of a collective end. Note that I could intentionally contribute to this collective end even if you didn't intentionally contribute to it, and indeed, even if you were completely unaware of my presence or activity.

It is not clear whether the participants' intentions overlap only if there is a single collective end that each intends to contribute to. Kutz rejects the Simple View, so such a requirement is at least not implied by the description analogy. ${ }^{9}$ According to Kutz, the participants' intentions can overlap "when the collective end component of their participatory intentions refers to the same activity or outcome and when there is a non-empty intersection of the sets of states of affairs satisfying those collective ends." (2000a, p. 20) The first part of this conjunction implies the second part, as well as that there is single collective end that each intends to contribute to. If the collective end components refer to the same token activity or outcome, then these components will be satisfied by the same state of affairs. But according to the second part, the participants may intend to contribute to distinct ends. Relatedly, Kutz states that "when we share a goal, the intentions of each

\footnotetext{
${ }^{9}$ That he rejects the Simple View is suggested by the claim that an "action is intentional under a description appropriately related (or identical) to a statement of the agent's goal." (Kutz, 2000b, p. 73). He also argues that an agent can intentionally contribute to a collective end without intending the realisation of that end, which also suggests a rejection of the Simple View (see 2000a, p. 25).
} 
are only satisfied by the performance or realization of the same token activity or outcome." (2000a, p. 5, n. 7, my emphasis) On the same page, however, he also suggests the much weaker criterion, according to which "two agents share a goal if there is at least one token activity or outcome, involving the actions of the other, whose performance or realization would satisfy the intentions of each." (2000a, p. 5) Recall, from the previous section, that Kutz also thinks that the participants must have a common conception of the collective end in order for their bringing it about to be jointly intentional.

Consider the following case in the light of Kutz's remarks about overlap:

Distributed Hunters: You and I are out hunting in the forest. There are two animals in the trees nearby. One rustles the leaves and the other casts a shadow on the forest floor. I want to catch the animal that rustles the leaves (Rustle, for short) and you want to catch the animal that casts the shadow (Shadow). Now, I believe that I will only catch Rustle if he is distracted by your pursuit of Shadow. Similarly, you believe that you will only catch Shadow if he is distracted by my pursuit of Rustle. Thus, I intend to contribute to the collective end that we catch Rustle (that is, the collective end that Rustle is caught as a causal product of my pursuit of Rustle and your pursuit of Shadow). You likewise intend to contribute to the collective end that we catch Shadow (that is, the collective end that Shadow is caught as a causal product of your pursuit of Shadow and my pursuit of Rustle). All this is common knowledge between us, so each believes that the combined pursuits of both will lead to both animals being caught, but each only 
intends to contribute to the catching of one of the animals. ${ }^{10}$ Our participatory intentions appropriately result in the outcome that we catch both Rustle and Shadow.

Do we here perform two intentional joint actions or none? The state of affairs where both Rustle and Shadow are caught is in the intersection of the set of states of affairs that satisfy my collective end and the set of states of affairs that satisfy your collective end. ${ }^{11}$ Furthermore, it is plausible that we each intentionally contribute to my collective end under the same conception and we each also intentionally contribute to your collective end under the same conception. Our activity is intentional for each under the description "our catching the animal that rustles the leaves": intentional for me because this is the collective end that I intend to contribute to, and intentional for you because the bringing about of my collective end is a salient foreseen side-effect of your contribution to your intended collective end. Our activity will likewise be intentional for each under the description "our catching the animal that casts the shadow": intentional for me because the bringing about of your collective end is a salient foreseen side-effect of my contribution to my intended collective end, and intentional for you because it is the collective end that you intend to contribute to. However, the collective end components of our participatory intentions do not refer to the same activity or outcome, which suggests that we are not jointly intentionally catching any animal.

There are grounds for thinking that Kutz would endorse the claim that you and

\footnotetext{
${ }^{10}$ On Kutz's account, participants' need not have common knowledge of each other's intentions (Kutz, 2000a, p. 6). In fact, they need not even have first-order expectations about each other's intentions or contributions (2000a, pp. 18-19). But the presence of such common knowledge is of course compatible with intentional joint action.

${ }^{11}$ I am assuming here that us catching both Rustle and Shadow is one state of affairs, namely a conjunctive state of affairs, which consists of the state of affairs of us catching Rustle and the state of affairs of us catching Shadow.
} 
I perform two intentional joint actions in Distributed Hunters. He claims that "a set of individuals can jointly intentionally $\mathrm{G}$ even though some [...] do not even intend to contribute to $\mathrm{G}$, but only know that their actions are likely to contribute to its realization." (2000a, p. 27) This may reflect that his ultimate aim with his account is to throw light on joint moral and legal responsibility. Arguably, we would each be morally and legally responsible for our catching Rustle and Shadow if, say, they belonged to an endangered animal species and there were a ban on hunting them. It also fits with the wide scope of Kutz's account. It is not only supposed to explain cases of small-scale highly interdependent intentional joint action such as that of two people hunting together, but also "genuine forms of collective action that we see in broader or more attenuated social contexts, such as voting, working in large organizations, supplying capital for risky venturescollective acts typical of the consolidated yet simultaneously highly individualized circumstances of modernity." (Kutz, 2000a, p. 2) ${ }^{12}$

However, setting aside the issue of how best to interpret Kutz, it is clear that we are not intentionally jointly catching Rustle nor intentionally jointly catching Shadow. In intentional joint action, each participant cares about the realisation of what the other intends to contribute to because this is what she herself intends to contribute to. They do not treat each others' agency merely as a resource to exploit for their own separate ends (emphasised by Kutz himself, see 2000a, p. 7). In contrast, in Distributed Hunters, I only care about whether we catch Shadow (what you intend to contribute it) insofar as this contributes to what I intend to contribute to, namely that we catch Rustle. And vice versa for you. While our catching

\footnotetext{
${ }^{12}$ Although in many such cases of collective action, there is of course a single collective endone referendum, one venture etc. - that each intends to contribute to.
} 
of the two animal is a case of parallel interdependent action, it is not a case of intentional joint action. This shows that simply transposing Davidson's thesis into a joint action context can be somewhat misleading. The transposition rests on an analogy and there are additional considerations that constrain theorising about joint action which aren't applicable in theorising about singular action.

On the most charitable construal of Kutz's account then, a joint action is an intentional joint action if and only if it is appropriately caused by the participants' overlapping participatory intentions, where this means (1) that there is a single collective end $E$ that each intends to contribute to and (2) that the participants have, at some level of granularity, a common conception $C$ of this end. In the next section, we will see that construed in this way, Kutz's account still fails to provide sufficient as well as necessary conditions for intentional joint action. Requirement (2) must be given a stronger interpretation, according to which the participants each intend to contribute to $E$ under the same conception $C$ of $E$. It is not sufficient that they each intentionally contribute to $E$ under the same conception $C$.

\section{The dilemma}

Consider the following variation on the Distributed Hunters case:

Distributed Hunters (Frege-Style): You and I are out hunting in the forest. This time, there is only one animal nearby. It rustles the leaves and casts a shadow. However, each of us is under the mistaken impression that the animal that rustles the leaves is not the animal that casts the shadow; each falsely believes that there are two animals. I want to catch the animal that rustles the leaves (for convenience, let's 
refer to the animal, when conceived this way, as 'Rustle'). You want to catch the animal that casts the shadow (let's refer to the animal, when conceived this way, as 'Shadow'). Now, I believe that I will only catch Rustle if Rustle is distracted by your pursuit of Shadow. Similarly, you believe that you will only catch Shadow if Shadow is distracted by my pursuit of Rustle. Thus, I intend to contribute to the collective end that we catch Rustle. You intend to contribute to the collective end that we catch Shadow (that is, to the collective end that I intend to contribute to, but conceived differently). Finally, we each accurately ascribe these intentions to each other. Our participatory intentions appropriately result in the outcome that we do catch the animal, the one that rustles the leaves and casts the shadow. However, each falsely believes throughout the hunt that there are two distinct animals, and that we intend to contribute to distinct collective ends.

According to Kutz's account, our catching the animal appears to be intentionally joint under the descriptions "our catching the animal that rustles the leaves" and "our catching the animal that casts the shadow". After all, there is (1) a single collective end $E$ that each intends to contribute to, and there are (2) two common conceptions of $E$, such that each intentionally contributes to $E$ conceived in each of these ways. However, just as it is clear that Distributed Hunters isn't a case of intentional joint action, so it is clear that our catching the animal in Distributed Hunters (Frege-Style) isn't an intentional joint action. Recall that intentional joint action is a form of intentional cooperation. In intentional joint action, each agent cares about the realisation of what the other intends because this is what she her- 
self intends. But in Distributed Hunters (Frege-Style), I only care about whether we bring about what you intend to contribute to (that is, that we catch Shadow) insofar as this contributes to bringing about what I intend to contribute to. From my mistaken perspective, this appears to be a distinct collective end (namely, that we catch Rustle).

The unified activity analogy from section 2 also indicates that our catching the animal isn't a case of intentional joint action. If I do not believe that there is a single end that each of my actions are directed to, then those actions are not intentionally jointly directed to that single end, and thus don't constitute an intentional singular activity. Similarly, if we don't believe that our catching the animal is a single end that each of our actions are directed to, then those actions are not intentionally jointly directed to that single end, and thus don't constitute an intentional joint action of catching the animal.

To rule out cases such as Distributed Hunters (Frege-Style), Kutz could add the requirement that the participants each have the same conception $C$ of $E$ in intending to contribute to $E$ (following Miller, 1995, p. 53). This conception $C$ of $E$ rationalises the contribution of each participant and makes it part of the intentional joint action. Indeed, perhaps this is how we ought to interpret Kutz's common conception requirement. Given that the participants accurately ascribe intentions to each other, including how the other conceives of the intended end, this allows Kutz to rule out Distributed Hunters (Frege-Style) since our participatory intentions represent our collective end under different conceptions; there is no conception of our catching the animal that rationalises my as well as your contribution. 
Unfortunately, if Kutz adds this requirement, he will be stuck on the second horn of the dilemma. With this same-conception requirement, Kutz appears to become unable to accommodate the following case:

Collective Hunters: You and I are out hunting in the forest. We have teamed up because we have complementary abilities. I am almost blind and you have a serious hearing deficiency. There is one animal in the canopy of the trees nearby. It rustles the leaves and also casts a shadow on the forest floor. I intend to contribute to our catching the animal that rustles the leaves. As I walk and listen to the rustling leaves, I frame my walking and listening as contributions to this collective end. You intend to contribute to our catching the animal that casts the shadow. As you walk and gaze at the shadows, you frame your walking and gazing as contributions to this collective end. Each correctly believes that there is a single collective end that each intends to contribute to, but neither represents under what conception the other represents this end. Our participatory intentions appropriately result in the outcome that we do catch the animal (the animal is very slow-moving, so we succeed despite our restricted abilities).

Collective Hunters appears to be a clear case of intentional joint action. You and I each care about the realisation of the other's intention. From our shared perspective, what the other intends to contribute to is what we ourselves intend to contribute to. Each also believes that there is single end that unifies our contributory actions into a complex joint activity. The fact that we conceive of this end in very different ways does not undermine our catching the animal from being 
jointly intentional. Thus, a condition that the collective end component of the participants' intentions must represent $E$ under the same conception should be rejected. It is not a necessary condition for participants' bringing about $E$ to be jointly intentional.

It might be objected that, actually, in Collective Hunters we do have a common conception of the collective end that we catch the animal, such that each intends to contribute to our catching the animal under that conception. After all, each conceives of the collective end as "the collective end that each intends to contribute to". However, our conception of (or belief about) our catching the animal as "our bringing about the collective end that each intends to contribute to" is an epiphenomenal upshot of the true belief of each that there is a single end that each intends to contribute to. The fact that the conception is shared plays no role in explaining or motivating our coordination with respect to our collective end that we catch the animal. What matters is that $I$ have the same conception of what you intend to contribute to and what I intend to contribute to, and that you have the same conception of what I intend to contribute to and what you intend to contribute to. This matters because the same conception here implies the same extension, that is, it implies that each of us believes or assumes that our catching the animal is a single end that each intends to contribute to. Whether we, inter-personally, have a common conception of the collective end appears to be neither here nor there. Furthermore, what we are trying to make sense of is the claim that our catching the animal is intentionally joint under the description "our catching of the animal" in Collective Hunters, not that it is intentionally joint under the description "our bringing about the collective end that each intends to contribute to". 
To summarise, Kutz's account either fails to set out sufficient conditions (that is, fails to rule out Distributed Hunters (Frege-Style)) or fails to set out necessary conditions (fails to accommodate Collective Hunters). Since Kutz claims to give necessary and sufficient conditions for "joint action as such", either Distributed Hunters (Frege-Style) or Collective Hunters will be a counterexample to his account.

\section{The doxastic single end condition}

By incorporating the doxastic single end condition in his account, Kutz can rule out Distributed Hunters (Frege-Style) while accommodating Collective Hunters and other cases in which the participants' intentions represent $E$ under different conceptions. According to this condition, each agent must believe or assume that $E$ is a single collective end that each intends to contribute to. Each participant must have some positively characterised attitude with mind-to-world direction of fit that represents $E$ as such a single end. Since the doxastic single end condition is satisfied in Collective Hunters, our catching the animal can be intentionally joint under the general description "our catching the animal" even in the absence of a common conception of our catching the animal. When the condition is satisfied, you and I intentionally contribute to an end which from our shared veridical perspective on the world is a single collective end.

Perhaps we could allow that this shared perspective isn't veridical. After all, the feature that makes our activity in Distributed Hunters into a case of mutual exploitation rather than intentional joint action isn't that there are in fact distinct collective ends that we intend to contribute to. Rather, what makes it a case of 
mutual exploitation is that we each believes this. Hence, once the doxastic single end condition has been introduced, perhaps there can be cases where only Kutz's weaker notion of overlap is applicable, according to which the collective ends that the participants intend to contribute to overlap "when there is a non-empty intersection of the sets of states of affairs satisfying those collective ends." (2000a, p. 20). If the participants' activity is such that it in fact realises the collective end of each, and each believes (mistakenly) that there is a single collective end that each intends to contribute to, then perhaps their activity might in some cases be an intentional joint activity (for an example, see Smith, 2006, pp. 280-281). At any rate, I take it that in paradigmatic cases at least, each participant's belief, assumption or presupposition that $E$ is a single collective end that each intends to contribute to will be true.

Could the dilemma I have presented be avoided in some other way? I doubt it. As a potential alternative, consider Miller's requirement that the single end of an intentional joint action must be "aimed at under more or less the same description by each agent." (2001, p. 58, my emphasis) I take this to be equivalent to allowing that the participants each intend to contribute to the collective end under somewhat different conceptions. Unfortunately, this more-or-less-the-same requirement is of no help. If "our catching the animal that rustles the leaves" and "our catching the animal that casts the shadow" are more or less the same conception of a single activity, then Distributed Hunters (Frege-Style) will not be ruled out. But if these are not more or less the same conception, then Collective Hunters won't be appropriately accommodated. Either way, Kutz would face a counterexample.

What about a weaker negatively characterised condition? Perhaps it is suf- 
ficient that no participant believes that $E$ is not a single collective end that each intends to contribute to. This would be sufficient if the point were merely to rule out and accommodate certain cases such as the ones I have presented. However, in light of the unified activity analogy and the fact that intentional joint action is a form of intentional cooperation, such a negatively characterised condition is arguably too weak. Each participant must have an occurrent attitude that is intentionally directed at the fact that $E$ is a single end that each intends to contribute to.

In the next section, I focus on demonstrating that Bratman's (2014) account of "shared intentional activity" faces a version of the dilemma I presented in the previous section. Arguably, Bratman's account is the best articulated account of intentional joint action available. It is also one of the most demanding accounts. By showing that Bratman needs to incorporate the doxastic single end condition, I hope to make it plausible that many other accounts need it too.

\section{Bratman's account of shared intention}

On Bratman's account, our catching the animal would be a shared intentional activity if it were caused and coordinated by our shared intention that we catch the animal, where a shared intention is a pattern of ordinary intentions and beliefs that play a role with respect to intentional joint action that is analogous to the role that intention plays with respect to individual action $(2014$, p. 27). Given Bratman's (1987) own theory of intention, this means that the pattern should be able to play a role in coordinating our plans and actions in pursuit of our catching the animal, as well as frame bargaining and shared deliberation about how to carry 
out the shared intention itself (2014, pp. 86-87).

According to Bratman (2014, p. 103), you and I have a shared intention that we $J$ if the following conditions are satisfied, where $J$ is a type of joint activity:

A. Intention condition: We each have intentions that we $J$; and we each intend that we $J$ by way of each of our intentions that we $J$ (so there is interlocking and reflexivity) and by way of relevant mutual responsiveness in sub-plan and action, and so by way of sub-plans that mesh.

B. Belief condition: We each believe that if the intentions of each in favour of our $J$-ing persist, we will $J$ by way of those intentions and relevant mutual responsiveness in sub-plan and action; and we each believe that there is interdependence in persistence of those intentions of each in favour of our $J$-ing.

C. Interdependence condition: There is interdependence in persistence of the intentions of each in favour of our $J$-ing.

D. Common knowledge condition: It is common knowledge that A.-D.

The core of Bratman's account is condition A. To illustrate, consider our shared intention to go to NYC (see Bratman, 2014, ch. 2). For condition A to be satisfied, each must intend that we go to NYC. Now recall that the notion of our going to $\mathrm{NYC}$ that figures in our intentions here cannot be the notion of shared intentional activity, since this would introduce a vicious analytical circularity that would render the account uninformative (see section 2). Bratman therefore appeals to notions that are "neutral with respect to shared intentionality" (2014, p. 46). For 
instance, he appeals to the notion of us "each intentionally [J-ing] in ways that avoid collisions" $(2009,47)$. But Bratman also appeals to the even weaker notion of us each $J$-ing in ways that avoid collisions (1999, p. 147). This weaker notion doesn't imply that each Js intentionally. Like Kutz's notion of a collective end, none of these notions imply that there is a single state of affairs that each is aiming at, nor that there is a single state of affairs that all are somehow directed at collectively. ${ }^{13}$ Given Bratman's weaker notion, this should be obvious. For example, we can bring it about that the carpet is ruined even if neither of us aims at ruining the carpet since each may ruin the carpet unintentionally. The ruining of the carpet is a causal product of our acts. When it comes to Bratman's stronger notion, it could be the case that we ruin the carpet even if only one or none of us aimed at ruining the carpet given that the Simple View is rejected. Bratman (1984) argues that an agent intentionally brings about some foreseen but unintended salient side-effects of her intended actions. Suppose I just intend to get across the room into the kitchen as quickly as possible but the ruining of the carpet is a foreseen but unintended side-effect of me getting across the room (I'm in a rush so I don't have time to remove my dirty shoes). Other things being equal, I would prefer that the carpet remained clean and tidy. In this case, I arguably intentionally ruin the carpet. But I nevertheless do not intend to ruin the carpet or aim at the ruining of the carpet. Now, suppose we add your activity to this. While I try to quickly get into the kitchen you, in parallel, intend to ruin the carpet. Furthermore, we each

\footnotetext{
${ }^{13}$ An unpublished paper by [removed for blind review] drew my attention to this fact. Ludwig's notion of joint action as "a single event of which there are multiple agents" (2007, p. 364), as well as Smith's (2011) notion of some agents $J$-ing "severally", does not imply that there is such a state of affairs either. In contrast, Butterfill's notion of a 'plural activity' is a notion of several agents' actions bringing about a state of affairs that each action is individually directed at (2012, pp. 3446). Gilbert's notion of a plurality of individuals that "emulate a single body" that $J \mathrm{~s}$ implies that there is single state of affairs that the group is directed at (2009, p. 180).
} 
intend to avoid colliding with the other. In this case, we each intentionally ruin the carpet in ways that avoid collisions, even if I don't aim at ruining the carpet.

So, each must intend that each of us (intentionally) go to NYC without colliding. Secondly, we must each intend this by way of our own and the other's effective intentions that we go to NYC. This requirement rules out cases where either of us tries to coerce the other by entirely bypassing their intentional agency. For example, it rules out the case where each intends that we go to NYC by way of throwing the other in the trunk of a car and drive there. Furthermore, each intends that we do it by way of sub-plans that are co-realisable, that "mesh". This elegantly rules out manipulation and deception. Suppose I intend that we go to NYC by train and you intend that we fly there (that is, our sub-plans do not in fact mesh). If I then intend that we go to NYC by train no matter what, irrespectively of what your sub-plans are, then I wouldn't intend that we go to NYC by way of meshing sub-plans. Thus, condition A rules out the case where I intend to fool you into thinking that the taxi that we jump into is heading for the airport rather than to its actual destination, that is, to the train station.

The beliefs cited by condition B ensure that each can have the intentions required by condition A without being criticizably irrational. If each believes that there is a kind of interdependence between our intentions, then we can each intend that we go to NYC by way of the other's intention that we go there. Typically, these beliefs are not mistaken, so Bratman also adds condition C. However, Bratman seems willing to allow that there may be cases of shared intention where neither condition B nor C is satisfied (2014, pp. 76-77). Recall that Bratman's aim is only to provide sufficient conditions for shared intention.

Condition D is motivated by appeal to the functional role that Bratman iden- 
tifies with shared intention: "[W]e need an element in our construction of shared intention whose functioning supports $[\ldots]$ thinking of each about our shared intention." (2014, p. 57). Without such thinking, we would not be able to engage in shared deliberation about how to carry out the shared intention. Bratman appeals to "an intuitive notion of common knowledge" but he also offers the following explication:

[I]t is common knowledge among A and B that $p$ just when (a) A knows that $p$, (b) $\mathrm{B}$ knows that $p$, (c) A knows that $\mathrm{B}$ knows that $p$, (d) $\mathrm{B}$ knows that $\mathrm{A}$ knows that $p$, (e) $\mathrm{A}$ is in an epistemic position to know that (d), (f) B is in an epistemic position to know that (c), and so on $[\ldots]$.

(Bratman, 2014, p. 5)

Initially, it may seem that Bratman's account is immune to the kind of dilemma that Kutz's account faces. This is because it is difficult to see how rational agents could end up in a situation where conditions A-D are all satisfied but where each believes that their $J$-ing isn't a single end that each intends. In the next section, I show that they could.

\section{Bratman's dilemma}

Consider the following elaborated version of Distributed Hunters (Frege-Style).

Bratmanian Hunters (Frege-Style): You and I are out hunting in the forest. I am set on catching the animal that rustles the leaves ('Rustle') and you are set on catching the animal that casts the shadow 
('Shadow'), but we each falsely believe that they are distinct individuals. Now, I believe that I will only catch Rustle if he is distracted by your pursuit of Shadow. Similarly, you believe that you will only catch Shadow if he is distracted by my pursuit of Rustle. Since this is a common belief between us, I predict that you will try to catch Shadow if I were to pursue Rustle. Similarly, you predict that I will try to catch Rustle if you were to pursue Shadow. Each believes that it is the combined pursuits of both of us that will lead to the animal (Shadow/Rustle) being caught.

In light of all this, I believe I can settle that we bring it about that Rustle is caught, and you likewise believe that you can settle that we bring it about that Shadow is caught. That is, I believe I can settle that we catch Rustle (in line with Bratman's weaker notion of "that we $J$ '), and you believe that you can settle that we catch Shadow. Hence, I can unilaterally and rationally intend that we catch Rustle and you can likewise unilaterally intend that we catch Shadow. For me to rationally intend this, I need not believe that your intention that we catch Shadow would track my intention that we catch Rustle in other circumstances, and the same is true of you.

If I know that you intend that we catch Shadow, then it also makes sense for me to intend that we catch Rustle by way of both my own intention and your intention that we catch Shadow, and likewise for you. I believe my only chance of realising my intention that we catch Rustle in these circumstances goes by way of your intention that we 
catch Shadow, even if I do not really care about whether Shadow is caught per se. Similarly, you believe your only chance of realising your intention that we catch Shadow goes by way of my intention that we catch Rustle. Since we are aware of this mutual dependency, each of us also believes that there is interdependence of persistence of our intentions.

Furthermore, we have nothing to gain from trying to deceive or manipulate each other. Hence, I intend that we catch Rustle by way of sub-plans for realising our intentions that mesh, and you intend that we catch Shadow by way of sub-plans for realising our intentions that mesh. (Bratman's conditions A and B are thus far satisfied. Now, Condition C and D could easily be satisfied too.) If either of us were to rescind our intention with respect to our catching of Rustle/Shadow, then the other will also rescind their intention. Finally, it is common knowledge between us that we have the beliefs and intentions specified by Bratman's conditions, including those involved in this state of common knowledge itself.

These intentions and beliefs appropriately cause us to catch the animal.

In this case, conditions A-D are arguably all satisfied. However, we each mistakenly believe that they are not satisfied. ${ }^{14}$ Our catching the animal in this case would, from the perspective of each, involve a kind of intentional mutual exploitation that is incompatible with intentional joint action. I only care about whether

\footnotetext{
${ }^{14}$ [Removed for blind review.]
} 
we bring about what you intend (that is, that we catch Shadow) insofar as this contributes to bringing about what I intend (namely, that we catch Rustle), an end that I believe is distinct from your end. And vice versa for you regarding what I intend. But intentional joint action is a form of intentional cooperation that is incompatible with participants having such attitudes. Hence, Bratman's account must be able to rule out Bratmanian Hunters (Frege-Style). The case is also a straightforward counterexample to Bratman's account in that it shows that conditions A-D fail to specify a pattern of attitudes that can play the functional role of shared intention. The pattern fails to support shared deliberation about how to carry out the shared intention since each is ignorant of the fact of our shared intention. On his own terms, Bratman thus fails to provide an adequate account of shared intention.

But is condition D really satisfied in Bratmanian Hunters (Frege-Style)? On one possible interpretation, condition $\mathrm{D}$ would only be satisfied if it were common knowledge between us that the conditions A-D for shared intention obtained. On such an interpretation, Bratman's account would already rule out all cases where agents fail to realise that their conceptions of $J$ are actually co-referential. This is because condition A specifies that there is a single end, the participants' $J$-ing, that is intended by each. If each participant knows that this condition holds, then each also knows (and believes) that their $J$-ing is a single end that is intended by each. In other words, the doxastic single end condition would then already be implicit in Bratman's account. On this interpretation, condition D would not be satisfied in Bratmanian Hunters (Frege-Style) since each of us there believes that condition A doesn't hold. 
This strong interpretation of condition D is suggested by Bratman's claim that the condition "induces a tight connection between shared intention and each participant's knowledge that the conditions obtain that constitute the shared intention." (2014, p. 58) However, it is the intentions and beliefs specified by the conditions that constitute the shared intention, not the conditions themselves. In a different paragraph, Bratman glosses condition $\mathrm{D}$ in terms of common knowledge "that the cited multiple components of the shared intention are in place." (2014, pp. 57-58) These components, I take it, are the intentions and beliefs of the participants rather than Bratman's conditions. This suggests another interpretation of condition $\mathrm{D}$, according to which it is sufficient that it is common knowledge between us that we have these intentions and beliefs that constitute the shared intention. In other words, condition D is satisfied if the following conditional holds: If an intention or belief of a participant is part of the pattern specified by A-D, then it is out in the open among the participants that the participant in question has this intention or belief. On this interpretation, condition D is satisfied in Bratmanian Hunters (Frege-Style). With respect to the intentions and beliefs specified by $\mathrm{A}-\mathrm{D}$, it is out in the open between us that we have these intentions and beliefs. Nothing stops us from having common knowledge of this fact; that the conditions A-D hold is a further fact that we are both in the dark about. ${ }^{15}$

While the explicit formulation of condition D is itself ambiguous with respect to these two interpretations, the latter weaker interpretation is arguably the preferred one. Shared intention is a socio-psychological phenomenon in virtue of

\footnotetext{
${ }^{15}$ It is true that the formation and persistence of our intentions relies on a belief that at most is a justified true belief, not knowledge. However, condition D does not-on either interpretationrule out that the intentions and beliefs specified by A-D have been formed in light of beliefs that don't constitute knowledge.
} 
which several agents' actions constitute a shared intentional activity. It is not supposed to also provide agents with theoretical insight concerning what characterises this socio-psychological phenomenon.

Note that conditions A-D could be satisfied even if the notion of our $J$-ing that figures in the content of our intentions is that of us each intentionally $J$-ing in ways that avoid collisions. In Bratmanian Hunters (Frege-Style), I plausibly believe that you are aware that you will bring it about that Rustle is caught if you pursue Shadow, and vice versa concerning what you believe about me. Since we have common knowledge of our mutual dependency, our expectations about the side-effects of our actions are salient to each. In light of this, I believe that our catching of Rustle will be a side-effect of your intention which you will bring about intentionally. And vice versa concerning you. If I believe this, then I can settle that each of us intentionally bring it about that Rustle is caught by way of your effective intention that we each intentionally bring it about that Shadow is caught, and vice versa for you. ${ }^{16}$

Now, Bratman actually makes a "simplifying assumption" regarding the participants' conception of $J$, which may appear to rule out Bratmanian Hunters (Frege-Style) and similar cases:

In appealing to [the condition that we each intend that we $J$ ] I am also making the simplifying assumption that in shared intention to $J$ the participants will have a common conception of $J$, that there is in this way a match in what is intended by each. [...] [T]his assumption of a common $J$ might be weakened at some point. Perhaps we can share

\footnotetext{
${ }^{16}$ Why would I intend this? Perhaps I want you to be agentially and not just causally coresponsible for Rustle being caught.
} 
an intention to go to NYC if I intend that we go to the city that is the home of the Yankees and you intend that we go to the city that is the home of the Mets. But these are matters we do not need to settle here.

(Bratman, 2014, p. 42)

With the additional supporting assumption that the participants accurately ascribe the common conception of our $J$-ing to each other, this simplifying assumption allows Bratman to set the counterexample I have presented aside. Without this supporting accurate-ascription assumption, we could easily construct a new counterexample in which we each intend to catch the animal that rustles the leaves but each mistakenly ascribe the intention that we catch the animal that casts the shadow to the other, and thus each could still believe that there is no single end that is intended by each. Here, we would conceive of our $J$-ing in the same way, so Bratman's simplifying assumption would hold, but we would nevertheless not have a shared intention to catch the animal. Hence, what is doing the work here is the combined result of Bratman's simplifying assumption and the supporting accurate-ascription assumption. The assumptions combine to ensure that $I$ have the same conception of what you intend and what I intend, and that you have the same conception of what I intend and what you intend. This combined result is a sort of intra-personal common conception requirement which is doing all the work here. Whether the participants have a common conception of their $J$-ing that holds inter-personally between them seems to be irrelevant to whether or not they have a shared intention to $J .^{17}$

\footnotetext{
${ }^{17}$ I reject Smith's (2006, p. 281) claim that "absent clear and public conceptual agreement, the systematic unity of our activities [that is characteristic of shared intentional activities] is blocked." Smith's claim is, I believe, based on the idea that an agent forms beliefs about another's intended end by first grasping under what conception the other represents the end and then working out the
} 
At any rate, if Bratman takes the simplifying assumption on board as an additional condition that falls within the scope of the common knowledge condition, then his account would not be able to appropriately accommodate an elaborated version of Collective Hunters. In this version, conditions A-D are all satisfied but my intention represents our catching the animal as "our catching the animal that rustles the leaves" and your intention represents it as "our catching the animal that casts the shadow". In intending to bring about that we catch the animal, we represent the intended end under different conceptions. Furthermore, each believes that there is a single state of affairs - that the animal is caught— that each intends that we bring about. There is no reason for claiming that we wouldn't have a shared intention of the very kind that Bratman gives an account of in such a case. If these interlocking intentions and beliefs appropriately result in us catching the animal, then our catching the animal is a shared intentional activity.

We can also imagine a case where you and I have a shared intention that we go to NYC even if we lack a common conception of our going to NYC. Suppose that I'm a Yankees fan who is unaware of the name of the team's home city. I want to go to the home city of the Yankees but I don't want to travel there on my own; I want a travel companion. You are a Mets fan who is unaware of the name of this team's home city. You want to go to the home city of the Mets and you also want a travel companion. As it happens, a mutual friend is aware of our

extension of the end based on this grasped conception. This view is mistaken. It is typically only after we have ascribed an intention to another agent that we try to work out - if it is necessaryunder what conception the agent represents the intended end (for discussion, see Blomberg, 2015, pp. 99, 100). This is not to deny that inter-personal conceptual divergence can have the potential to block shared intentional activity. For example, if each of us falsely believes that there are two animals in Collective Hunters and we become aware of the fact that I intend that we catch the animal that rustles the leaves and you intend that we catch the animal that casts the shadow, then the belief of each that there is single end that is intended by each might be undermined. 
coinciding interests (she knows that NYC is the home city of both the Yankees and the Mets). Our mutual friend tells me: "I've got a friend who will join you! He wants to go there too." She tells you the same. Knowing both of us well, our mutual friend reliably predicts that we will join each other. She then hires a car with a driver and instructs the driver to take us to NYC the following morning. She also arranges for us to meet up at the car the next morning. As we meet the next morning, I exclaim: "Nice to meet you. Now, let's go together!", to which you reply: "Alright, let's go together!". We shake hands in agreement, step into the car, and off we go to NYC.

Here, each intends that we go to NYC, although neither of us have this conception of our destination. We can suppose that as we step into the car, each intends that we do this by way of the other's effective intention and by way of meshing sub-plans. Furthermore, it is common knowledge between us that we have these intentions and beliefs. However, we don't have a common conception of our going to NYC, nor do we have a clue about what conception the other has of the single end that is intended by each.

Now, echoing the line of thought at the end of section 4 , there is a common conception of our $J$-ing in Collective Hunters which is such that it, were it required, does rule out Bratmanian Hunters (Frege-Style). This is also a common conception in the case where we go to NYC but conceive of our destination differently. This is the conception of "our bringing about the single state of affairs that each intends that we bring about". Again, the conception is an epiphenomenal upshot of our shared intention plus the belief of each that our $J$-ing is a single end intended by each. As Bratman puts it, "[w]e seek [...] a construction of interconnected intentions and other related attitudes of the individuals" that can play 
the role of shared intention $(2014$, p. 32$)$. The common conception that we are considering is not part of Bratman's construction of conditions A-D, nor does it emerge from this construction. Furthermore, it is not in virtue of the fact that this conception is shared between us that there is a match in what is intended by each.

Since Bratman's account consists only of sufficient conditions, these cases do not present him with counterexamples. Nevertheless, since the account is supposed to characterise what is involved in our actual everyday shared activities, it would be a problem for Bratman if many such activities couldn't be appropriately accommodated by his account (see Bratman, 2014, pp. 3, 26). Plausibly, we often have different conceptions of our $J$-ing without being aware of what these differences are. This suggests that Bratman should drop his simplifying assumption.

\section{Saving Bratman's account}

What Bratman needs is an additional condition that is brought, as follows, within the scope of the common knowledge condition:

D'. Doxastic single end condition: We each believe that our $J$-ing is a single end that is intended by each.

E. Common knowledge condition: It is common knowledge that A-C, D' and E.

A-C, D' and E are sufficient for shared intention. ${ }^{18}$ If the conditions are satisfied, then I care about the realisation of what you intend in the right way, and that you

\footnotetext{
${ }^{18}$ Bratman's account already contains a condition E. This "mutual responsiveness condition" now becomes condition F. If this condition is also satisfied, then the shared intention results in the participants' $J$-ing in such a way that it is their shared intentional activity.
} 
care about the realisation of what I intend in same way. Since I believe that our $J$-ing is a single end that is intended by each, I care directly about what you intend and you similarly care directly about what I intend. Cases such as Bratmanian Hunters (Frege-Style), which are characterised by mutual exploitation rather than genuinely joint action, are thus ruled out. ${ }^{19}$

The specified pattern of intentions and beliefs also ensures that we know that we have our shared intention. It therefore supports shared planning and deliberation concerning how to carry out the shared intention. In other words, the pattern can now play a role with respect to intentional joint action that is analogous to the role that intention plays with respect to individual action. In this way, the doxastic single end condition is also supported by the intention analogy.

In addition, the doxastic single end condition makes Bratman's simplifying assumption superfluous. It doesn't at all constrain what conceptions we have of our $J$-ing. In line with Bratman's conservative approach to shared agency, the condition achieves all this without introducing any new fundamental notion that isn't already part of his account. It is thus compatible with Bratman's attractive thesis that shared intentional activity is metaphysically and conceptually continuous with individual planning agency.

\section{Conclusion}

Something is missing from several influential accounts of intentional joint action. These accounts need an extra condition to provide sufficient conditions for shared

\footnotetext{
${ }^{19}$ If an argument in Butterfill (forthcoming) is sound, then adding the doxastic single end condition wouldn't suffice for ruling out such mutual exploitation. I will not address this here, but see Bratman's (2014, pp. 100-101) response to Christine Korsgaard's objection that shared intention involves a sort of mutual exploitation.
} 
intention and intentional joint action. In order to perform an intentional joint action, each participant must believe or assume that there is a single end that is intended by each, or that each intends to contribute to. I have illustrated why this condition is needed by showing that accounts of intentional joint action must rule out Frege cases such as Distributed Hunters (Frege-Style) while at the same time accommodating cases such as Collective Hunters.

The condition identifies a feature that is at the very heart of out concept of intentional joint action. How do we know this? We know this in part because it ensures that cases of intentional joint action involve a kind of reciprocity: Each cares about what all intend since this is the very end that they themselves each intend to bring about or contribute to. Furthermore, a number of analogies between the intentional joint and intentional singular action-all of which have an important place in the philosophy of joint action-support the condition. These considerations and analogies strongly suggest not only that the doxastic single end condition is needed for this or that account to provide sufficient conditions, but they also support the claim that it is a necessary condition on intentional joint action as such. 


\section{References}

Adams, F. (1986), 'Intention and intentional action: The simple view*', Mind \& Language 1(4), 281-301.

Alonso, F. (2009), 'Shared intention, reliance, and interpersonal obligations', Ethics 119(3), 444-475.

Blomberg, O. (2015), 'Shared goals and development', Philosophical Quarterly 65(258), 94-101.

Blomberg, O. (forthcoming), An account of Boeschian cooperative behaviour, in C. Misselhorn, ed., 'Collective Agency and Cooperation in Natural and Artifical Systems', Philosophical Studies, Springer Verlag.

Bratman, M. (1984), 'Two faces of intention', The Philosophical Review 93(3), 375-405.

Bratman, M. (1987), Intention, plans and practical reason, CSLI Publications.

Bratman, M. (1999), Faces of Intention: Selected Essays on Intention and Agency, Cambridge University Press.

Bratman, M. (2009), Shared agency, in C. Mantzavinos, ed., 'Philosophy of the Social Sciences: Philosophical Theory and Scientific Practice', Cambridge University Press, pp. 1-22.

Bratman, M. (2014), Shared Agency: A Planning Theory of Acting Together, Oxford University Press. 
Butterfill, S. (2012), 'Joint action and development', The Philosophical Quarterly 62(246), 23-47.

Butterfill, S. A. (forthcoming), Planning for collective agency, in C. Misselhorn, ed., 'Collective Agency and Cooperation in Natural and Artifical Systems', Philosophical Studies, Springer Verlag.

Chant, S. (2007), 'Unintentional collective action', Philosophical Explorations 10(3), 245-256.

Chant, S. R. (2006), 'The special composition question in action', Pacific Philosophical Quarterly 87, 422-441.

Dalton, P. (1995), 'Extended action', Philosophia 24(3), 253-270.

Davidson, D. (2000), 'Agency', Essays on Actions and Events (ch. 3).

Gilbert, M. (2009), 'Shared intention and personal intentions', Philosophical studies 144(1), 167-187. 9372.

Kutz, C. (2000a), 'Acting together', Philosophy and Phenomenological Research 61(1), 1-31.

Kutz, C. (2000b), Complicity: Ethics and law for a collective age, Cambridge University Press.

Laurence, B. (2011), An Anscombian approach to collective action, in A. Ford, J. Hornsby and F. Stoutland, eds, 'Essays on Anscombe's Intention', Harvard University Press, chapter 10, pp. 270-296. 
Ludwig, K. (2007), 'Collective intentional behavior from the standpoint of semantics', Nous 41(3), 355-393.

Miller, S. (1995), 'Intentions, ends and joint action', Philosophical Papers 24(1), 51-66.

Miller, S. (2001), Social Action: A Teleological Account, Cambridge University Press.

Pacherie, E. (2011), 'Framing joint action', Review of Philosophy and Psychology 2(2), 173-192.

Petersson, B. (2007), 'Collectivity and circularity', Journal of Philosophy 104(3), 138-156.

Pettit, P. and Schweikard, D. (2006), 'Joint actions and group agents', Philosophy of the Social Sciences 36(1), 18-39.

Roth, A. (2004), 'Shared agency and contralateral commitments', The Philosophical Review 113(3), 359-410. 4147974.

Searle, J. (2010), Making the Social World: The Structure of Human Civilization, OUP Oxford.

Searle, J. R. (1990), Collective intentions and actions, in P. R. Cohen, J. Morgan and M. E. Pollack, eds, 'Intentions in Communication', MIT Press, pp. 401415.

Searle, J. R. (1992), The Rediscovery of the Mind, reissue edn, MIT Press. 
Smith, M. N. (2006), 'The law as a social practice: Are shared activities at the foundations of law?', Legal Theory 12, 265-292.

Smith, T. (2011), 'Playing one's part', Review of Philosophy and Psychology 2(2), 213-244.

Tuomela, R. (2007), The Philosophy of Sociality: The Shared Point of View, OUP USA.

Tuomela, R. and Miller, K. (1988), 'We-intentions', Philosophical Studies 53(3), 367-389. 